\title{
Kitap Değerlendirmesi: Apaydın, Yasin. Metafiziğin Meselesini Temellendirmek: Tecrîd Geleneği Bağlamında Umûr-ı Âmme Sorunu (İstanbul: Endülüs Yayınları, 2019). ISBN: 978-605-2105-45-0
}

\section{Zeynelabidin Huseyni ${ }^{1}$ (1)}

Klasik felsefî ansiklopedik eserlerin önemli bir başlı̆̆ını oluşturan ve ontolojiden teolojiye kadar farklı alanlardaki meselelerin anlaşılmasında kritik bir yer işgal eden umur-ı âmme teriminin mâhiyeti ve niteliklerine dair tahlillere akademik araştırmalarda yeterince yer verilmediği söylenebilir. Halbuki kavramların mâhiyetine dair tetkikler, özellikle ilgili alanın okuyucusu için yeni ufuklar açılmasına katkı sağlamaktadır. Felsefî kavramların salt sözlük anlamlarına dayanarak yapılan genel tahlillerin, metinlerin meramını anlamada ve dakik ayrımları görmede yeterli olmadığı açıktır. Yasin Apaydın'ın Metafiziğin Meselesini Temellendirmek: Tecrîd Geleneği Bă̆lamında Umûr-ı Âmme Sorunu adlı çalışması; varlık, yokluk, mâhiyet, zorunluluk-imkân-imkansızlık, hudûs, kıdem, illet-malûl gibi ontolojiye dair bâhislerin kavramsal karşıllğı olan umûr-1 âmmenin kökeni, mâhiyeti, nitelikleri ve kapsamını müteahhirîn döneminin etkili metinlerinden olan Tecrîdü'l-akâid geleneğinden hareketle analiz etmektedir.

Genellikle ikincil literatürde varlık, mâhiyet, illiyet gibi umûr-1 âmmeye karşı1ık gelen meselelerin tikel olarak çalışıldığı görülür. Bununla birlikte felsefeye dair eserlerde çok önemli felsefî̀ meselelerin incelendiği kilit ve kurucu bir bölüm olmasına karşl1ık hangi tanım ve içeriğe göre umûr-1 âmme kavramsallaştırmasının yapıldığı önem arz eden esas sorunu teşkil eder. Zira kavramın mâhiyeti, ontoloji bahislerinin içeriğinden diğer metafizik bir çok meseleye değin etkin bir rol oynar. Apaydın'ın eserinin karakteristik özelliği, umûr-1 âmmenin tanım ve nitelikleri üzerine yoğunlaşmasıdır. Eserin ilk bölümünde Tecrîdü'l-Âkâid ve Tecrîd geleneğinin oluşumu çalışmanın amacına matuf olarak şerh, haşiye, müstakil umûr-1 âmme risaleleri bağlamında analiz edilmiştir. İkinci bölümde umûr-1 âmmenin hazırlayıcısı olarak metafizik ve kelâmın mevzûsu ve meselelerine dair tartışmalar ve

1 Sorumlu Yazar: Zeynelabidin Huseyni (Arş. Gör.), İstanbul Üniversitesi, ilahiyat Fakültesi, İstanbul, Türkiye.

E-posta: zeynelabidin.huseyni@istanbul.edu.tr ORCID: 0000-0002-3214-9219

Atrf: Huseyni, Zeynelabidin. “Metafiziğin Meselesini Temellendirmek: Tecrîd Geleneği Bağlamında Umûr-ı Âmme Sorunu.” Yasin Apaydın’ın Metafiziğin Meselesini Temellendirmek: Tecrîd Geleneği Bağlamında Umûr-ı Âmme Sorunu adlı eserinin tanıtımı. darulfunun ilahiyat 30, 2 (2019): 561-566. https://doi.org/10.26650/di.2019.30.2.0067 
mevcutların taksimi kronolojik olarak incelenmiştir. Yazar, çalışmanın esas kısmını teşkil eden üçüncü bölümde ise umûr-1 âmmenin tanımı ve niteliklerine dair farklı yaklaşımları ortaya koymaya gayret etmiştir.

Nasîrüddin Tûsî’nin (ö. 672/1274), İbn Sînâ (ö.428/1037) felsefesine karşı ilgisi bilinmekle birlikte felsefi düşüncenin kelâm disiplinine adaptasyonunu sağlayan bir isim olması, Tecrîdü'l-Akâid adlı eserinin farklı ekollere mensup isimler tarafından şerh edilmesini sağlamıştır. Nitekim yazarın da belirttiği üzere Tecrîd metni kadar İslam dünyasının farklı kesimlerinde ciddi bir ilgiye mazhar olan başka bir metin bulmak pek de kolay gözükmemektedir. (s. 49) Öyle ki farklı mezhep ve mekteplere mensup düşünürlerin kaleme aldıkları eserleriyle bir açılım ve sürekliliği tesis ettikleri pekala söylenebilir. Bundan dolayı eserin ilk bölümünde altı şerh, altı tane haşiyenin yanı sıra altı tane de umûr-1 âmme risalesi kısaca tanıtılarak umûr-1 âmme sorunu bağlamında ele alınmıştır. Apaydın'a göre umûr-1 âmme risaleleri denildiğinde genellikle ontolojiye dair meseleleri ihtiva eden bütün çalışmalar bu kavramsallaştırmanın altına dahil edilebilmektedir. Ancak yazar, umûr-1 âmmeye dair meseleler ve onlara ilişen halleri ihtiva eden risaleler yerine daha spesifik bir tercihle bizâtihi mezkûr kavramın tanımı, kapsamı, nitelikleri ve önemi üzerinde duran literatürü dikkate almıştır. Apaydın, bu bağlamda ele alınan risalelerin müstakil bir yazım türüne dönüştüğünü ve özellikle Osmanlı coğrafyasında zuhur ettiğini iddia etmektedir. Bunun nedeni ise Osmanlı öncesinde bu konuya dair tartışmaların belli bir olgunluğa erişmesiyle Tecrîd ve Mevâkıf gibi metinlerin ders kitapları olarak kullanılmasıdır. (s. 129) Yazarın ulaştığı umûr-1 âmme risalelerinin tamamının Osmanlı coğrafyasında kalan simalar tarafindan yazılması, bu risalelerin Osmanlı coğrafyasında neşvünema bulma sebeplerinin daha ayrıntılı olarak araştırılmasını gerektiren bir husustur. Dolayısıyla hatırı sayılır bir birikimi ifade eden Tecrîd geleneğindeki birçok felsefi meseleden ve bunların sonucu olarak ortaya çıkan umûr-1 âmme risaleleri geleneğinden bîhaber kalmak, müteahhirîn döneminin sürekliliğini ve müstakil felsefi risalelerin arka planını ıskalamaya yol açacaktır.

Müteahhirîn dönemindeki felsefî ansiklopedik eserlerde umûr-1 âmme terimi ve sorununa yer verilmekle birlikte, İslam felsefesinin erken döneminde umûr-1 âmme sorununun dolaylı olarak gündeme geldiği görülür. Yazarın umûr-1 âmme sorununun klasik dönemdeki bağlamına da çalışmasında yer vermesi, bütünselliği ve farklı açılımları görebilmek adına önemlidir. Metafiziğin isimlendirilmesi, konusu ve meseleleri arasındaki ilişkinin keyfiyeti, zâtî araz problemi, varlıkların taksimine yönelik izâhatlar meselenin serencamını ve seyrini görebilmek adına ele alınan ana temalar olmuştur. Dolayısıyla umûr-1 âmme terimi ilk kez Fahreddin Râzî’nin (ö. 606/1210) el-Mebâhisü'l-meşrikiyye eserinde müstakil olarak yer alsa da erken dönemden beri farklı tartışmalar bağlamında bu konuya değinildiği söylenebilir. 
(s. 135) Özellikle Fârâbî’nin (ö. 339/950) metafiziğin konusunun sınırlarını tayin etme çabası ve bunun daha sonra İbn Sînâ tarafından geliştirilerek tevarüs edilmesi, metafiziğin konusunun meselelerin tayin edilmesindeki başat rolünü görmemize imkan verir. Tek küllî ilim olma payesinin metafiziğe verilmesiyle metafiziğin meselelerinin de küllî olma hüviyetine bürünmesi sağlanmıştır. Ayrıca metafiziğin genellik ölçütüne sahip olması, bu özelliği taşıyan varlık, birlik gibi kavramların karşıtlarının da incelenmesini gerektirmiştir. (s. 141) Fârâbî'nin metafiziğinde umûr-1 âmme kapsamına giren meseleler her ne kadar ortaya konulmuşsa da bunlara dair bir kesinliğin belirtilmeyişi de sonraki dönemlerde farklı tercihlerin ortaya çıkmasının zeminini oluşturur. Apaydın'a göre Fârâbî, umûr-1 âmme ibâresini lafzen kullanmış olsa da daha çok kavramın sözlük anlamını kastetmektedir. (s. 148) Ancak bu durum, Fârâbî’nin meselenin gelişimine katkısını ve kökenlerini tespitte ayırt edici pozisyonunu ortadan kaldırmamaktadır. Akabinde İbn Sînâ'nın umûr-1 âmme arasında sayılan kavramları harekete konu olması mümkün olup ondan müstakil olarak da bulunabilen şeklinde nitelendirmesi; metafiziğin konusu, meselesi ve ilkelerini zabturabt altına almasi; her ne kadar terim anlamıyla umûr-1 âmme kavramını kullanmamış olsa da Metafizik adlı eserini metafiziğin meselelerini çağrıştıracak şeklinde tesis etmesi önemli açlımlar olarak dile getirilmektedir. (s. 152, 160) Aynı şekilde İbn Sînâ takipçilerinden Behmenyâr'ın (ö. 458/1066) metafiziğin neleri içerdiğine dair ifadeleri ve Levkerî’nin (ö. 517/1123) ilm-i küllîyi Fârâbî'de olduğu gibi ayırt etmesi dikkat çeker. İlk başta kendi başına bir ilmi disiplinin adı olmaktan ziyade metafiziğin küllî bir disiplin oluşunu vurgulayan ilm-i küllî, İbn Sînâ ve sonrasında metafiziğin teolojiyle birlikte kurucu unsurunu oluşturmuştur. (s. 170) Yazar'ın bütün gayreti, metafiziğin konusu ve meselesine dair Meşşâi arka planda yapılan tartışmaların umûr-1 âmme meselesinde hazırlayıcı bir rol üstlendiğini göstermektir. Aynı şekilde kelâm geleneğinde her ne kadar aralarında nüanslar olsa da özelikle Urmevî’nin (ö. 682/1283) ve Şemsüddin Semerkandî’nin (ö. 702/1303) metafizikte bir mesele olarak varlı̆g ispat edildikten sonra kelâmın konusu olarak Zorunlu Varlığ̣ tayin etmeleri, Seyyid Şerîf Cürcânî (ö. 816/1413) gibi isimler tarafından sert eleştirilere maruz kalmalarına yol açmıştır. Bu yaklaşıma nazaran Adudiddin İcî (ö. 756/1355), Cürcânî ve Teftâzânî (ö. 792/1390) gibi isimler ise kelâmın konusu olarak malûmu kabul etmişlerdir. Konunun değişmesiyle kelâmın meseleleri içerisine nelerin girip girmeyeceği meselesi, tartışılan önemli bâhisleri oluşturmuştur. Bütün bu isimlere nazaran Tûsî Tecrîd metninde kelâmın konusu tartışmalarına girmemiştir. İlk şarih İbnü'l-Mutahhar el-Hillî (ö.726/1325) de her ne kadar metafiziğin ve kelâmın konusunu mutlak varlık olarak tayin etse de Tecrîd şerhinde bu konuya yer vermemiştir. (s. 203) Bir diğer önemli şârih Şemsüddîn Isfahanî (ö. 749/1349) ise kelâmın konusunu Allah'ın zâtı ve yaratılanların zâtları şeklinde ifade etmiştir. (s. 206) Ancak Tecrîd geleneğinde yazarın da belirttiği üzere 
kelâmın konusu ve meselelerinin umûr-1 âmme tartışmalarına katkısını görebilmek adına geniş açıklamaları Abdürrezzâk Lâhîcî'nin (ö. 1072/1661) şerhinde görmek mümkündür. (s. 208)

İkinci bölümün son başlığı olarak mevcutların taksimi ile umûr-1 âmme arasındaki ilişki irdelenmiştir. Özellikle Râzî’nin Muhassal isimli eserinde felâsife ve mütekellimînin bu konuya ilişkin görüşlerini ayrı ayrı ortaya konulmasının akabinde Semerkandî, Kâdî Beyzâvî (ö. 685/1286) ve Hillî’nin de aynı şekilde karşılaştırmalı olarak mevcutları taksim etmeye özen göstermeleri umûr-1 âmme meselelerinin arka planında hazırlayıcı bir unsur olarak gösterilmiştir. (s. 216) Ancak Apaydın'a göre Tecrîd geleneğinde sistematik ve geniş bir perspektifle mevcudatın taksimini ön plana çıkaran kişi Şemseddin Isfahânî olmuştur. (s. 224) Esas gaye mevcutlara hamledilen umûr-1 âmmenin şamil olduğu dairenin gösterilmesidir. Dolayısıyla ikinci bölümde farklı felsefî ekollerin metafiziğe dair tasavvurlarının belirginleştirilmesiyle metafiziğin konusu ve meseleleri arasındaki ilişkiye dair yorumlarının serencamı ortaya konulmuştur.

Çalışmanın üçüncü bölümünde umûr-1 âmmenin felsefî analizine ilişkin esas soru-n-lar tartışılmaktadır. Bu bağlamda umûr-1 âmmenin farklı tanımları arasındaki ince ayrımlar, içerik ve özelliklerinin neler olduğu, neye binâen diğer felsefî araştırmaların önüne geçtiği dikkat çeken sorulardır. Apaydın'ın belirttiği üzere Râzî ve Ebherî gibi isimler umûr-1 âmme terimine ve bazı izâhatlara eserlerinde yer vermekle birlikte terimin mâhiyetine ve tanımına dair tahlillerde bulunmamışlardır. (s. 240) Çalışmanın esas metni olan Tecrîd metninde de Tûsî, umûr-1 âmmenin tanımını yapmayıp doğrudan meselelerin tahliline geçmiştir. Apaydın'a göre Beyzâvî umûr-1 âmme yerine umûr-ı külliye kavramını, Semerkandî ise umûr-ı şâmile ibaresini tercih etse de bu kullanımlar arasında mânâ açısından bir farklılık görünmemektedir. (s. 244)

Umûr-1 âmmenin klasik gelenekte "mevcutların kısımlarından birine özgü olmama (ihtisâs)", "tek başına mevcutların tümünü ya da çoğunu kapsama (şümûl)", "tek başına olmayıp karşıt kavramı ile birlikte ilmi bir amaç taşımak suretiyle mevcutları kapsama (tekâbül)" şeklinde üç farklı tanımının yapıldığını belirten Apaydın, buna ilave olarak tarihsel açıdan ilk tanımlama girişimini ifade eden "mevcutların tümünde ya da çoğunda ortak olan (iştirâk)" şeklindeki tanımın da ilave edilebileceğini aktararak bunları sırasıyla analiz etmiştir. (s. 246) Zorunlu ile mümkün varlıklar arasında ortak bir yüklenmeye elverişliliği ifade eden ortaklık yorumuna dayalı tanımlamayı ise Kâtîbî'nin Münassas eserinde ve Burhânüddîn elİbrî (ö. 743/1342) ile Hacı Paşa'nın (ö. 827/1424) Tevâlı şserhlerinde bulmaktayız. (s. 250) Tecrîd şârihleri arasında ise ortaklığa dair tanımlamayı, Şemseddin Isfahânî’nin 
Şerhu'l-Misbâh adlı eserinde görmek mümkündür. Bu tanıma dayalı önemli ayrıntı madûm ve illet-malûl kavramlarına dair araştırmaların da dikkate alınmasıdır. (s. 245) Mevcutların çoğunu kapsayan şeyleri ifade eden kapsayıcılık tanımına ilk yer verilen kaynak Semerkandî'nin Sahâif'i ve şerhi Maârif'tir. Isfahânî ise Tecrîd şerhinde bu sefer umûr-1 âmmeyi kapsayıcılık yorumuna referansla tanımlamıştır. Öyle ki yazara göre aslında ortaklık ve kapsayıcılık yorumları Isfahânî tarafindan aynı şeyi farklı cihetlerle ele alan iki itibar olarak değerlendirilebilir. (s. 256-257) Müteahhirîn döneminde Tecrîd şârihi Şemseddin İsferâyînî (ö. 740/1340) bu yoruma Tefrîdü'l-itimâd eserinde yer verirken, eleştirel katkılarıyla Teftâzânî'nin ilk iki yorumu birbirine yakın görmeye yönelik bir eğilim içerisinde olduğu dile getirilmiştir. (s. 262) Üçüncü tanım ise İcî’nin Mevâkıf eserinde rastlanan Zorunlu, cevher ve araz gibi mevcutların kısımlarından birine özgü olmamayı ifade eden özgülük/ihtisâs yorumudur. Illk iki tanıma nazaran bu tanımın daha az kişi tarafından savunulduğunu hatta Cürcânî'nin Tecrîd haşiyesinde zayıf bir ihtimal olarak görüldüğünü belirten Apaydın'a göre esas olarak bu tanımı benimseyen kişi Ali Kuşçu'dur (ö. 879/1474). (s. 270) Umûr-1 âmmenin karşıtları ile birlikte mefhumları kuşatması şeklinde ifade edilen son tanımlama girişimi Cürcânî’ye atfedilmektedir. Özellikle illet, imkân, zorunluluk, yokluk gibi kavramların müstakil olarak mevcudun tüm kısımlarını içermemesinden dolayı, asıl mefhuma tabi olarak bunların da umûr-1 âmme şemsiyesi içerisine dahil edilmesi amacı güdülmüştür. (s. 273) Sonuç olarak umûr-1 âmmeye dair dört farklı tanımın tasnif edilmesi, yazarın da belirttiği üzere bunların birbirleriyle geçişkenliklerinin olmadığını göstermez. Ayrıca tanımların Tecrîd geleneği başta olmak üzere farklı filozoflar tarafından zamanla eleştiriye tabi tutularak geliştirildiği veya eksik yönlerinin ön plana çıkartıldığ 1 görülmektedir. (s. 277)

Son olarak umûr-1 âmmenin farklı tanımlama girişimlerinin bir sonucu olarak farklı açılardan niteliklerine değinen yazar, zâtî arazlık, ilke'lik ve ikinci akledilirler olmayı ön plana çıkarmıştır. Bu bağlamda bu nitelemelerin belirli bir şema dahilinde dile getirilmediği, yazarın uğraşı ve okumaları sonucunda satır aralarında tespit ettiğini belirtmemiz gerekir. (s. 280) Bir ilmin meselelerinin ona ilişen zâti arazlar olmasına binâen metafiziğin meselelerini ihtiva eden umûr-1 âmmenin zâtî araz olmayla arasındaki ilişkinin açığa çıkartılması önem arz eder. Ancak yazarın belirttiği üzere metafiziğin meselesi olarak mutlak mevcudun zâtî arazlarını, sadece umûr-1 âmmeye dair meselelere indirgemek yanlıştır. (s. 284) Müteahhirîn dönemde zâtî arazın umûr-1 âmmeyle ilişkisine dikkat çeken ve farklı tanımlama girişimlerinin arkasında bu irtibatın sağlıklı bir şekilde inşa edilememesi olduğunu düşünen kişi Molla Sadra'dır. Öyle ki Fârâbî ve İbn Sînâ gibi isimlere nazaran sonraki dönemlerde bu irtibat, güçlü bir şekilde dile getirilmemiştir. (s. 288) Zâtî 
araz ve umûr-1 âmme arasındaki ilişkinin tespiti konusunda spesifik çalışmalara ihtiyaç olduğu söylenebilir.

Tecrîd geleneğinde umûr-1 âmmenin mebâdî olma niteliğini vurgulayan isimler Isfahânî ve İsferâyânî olmuştur. Bu özellik, umûr-1 âmmeye ilişkin meselelerle metafizik ilmine başlanmasının da gerekçesini oluşturur. Mevcudatın tamamına veya çoğuna yüklenebilmesinden dolayı genel olma hüviyetinin ağır basmasından dolayı umûr-1 âmme asıl mesabesindedir. (s. 291) Son olarak umûr-1 âmmenin ilişkili olduğu bir diğer önemli niteliği, ikinci akledilirler olarak zikredilmiştir. Isfahânî, ikinci akledilirler için "hariçte tahakkuku olmayıp zihinde ilk akledilirlere ilişmesi ve hariçte mutabık bir suretinin bulunmaması" şeklinde iki önemli kriter koymuştur. (s. 304) Erken dönemde Fârâbî ve İbn Sînâ'nın umûr-1 âmmeyi zihinde vuku bulan genel manalar olarak değerlendirdiğini belirten Apaydın'a göre bu ilişkiyi açık bir şekilde Behmenyâr ifade etmiş, Sühreverdî de umûr-1 âmmeye ilişkin kavramları itibarî olarak görmüştür. (s. 300-301) Tecrîd metninin müellifi Tûsî de birlik ve çokluk gibi kavramların ikincil akledilirlerden görülmesi kanaatindedir. Ayrıca Ali Kuşçu'nun Tûsî’ye, Devvânî’nin Ali Kuşçu'ya yönelik ikinci akledilirler meselesi hakkındaki itirazları önemli bir felsefî tartışma mecrası olarak dile getirilmiştir. (s. 305-308)

Bir felsefî sorun olarak umûr-1 âmmenin mâhiyeti ve niteliklerine yönelik klasik dönemden müteahhirîn dönemine kadarki süreci başarılı bir şekilde ortaya koyan Apaydın'ın bu çalışması, İslam felsefesi disiplini için önemli açılımları beraberinde getirmiştir. Öncelikle şerh, haşiye ve müstakil risaleler gibi birincil el kaynaklardan ve yazma eserlerden hareketle tezlerini temellendirmesi, genel ve özetleyici bir üslup yerine tasniflerle müteahhirîn döneminin zor pasajlarını anlaşılır kılması okuyucu için bir avantaj teşkil etmektedir. Ayrıca bu çalışma örneğinde gittikçe spesifikleşen tez çalışmalarının konuların detaylarının ele alınabilmesi açısından sağladığı imkanlar açık bir şekilde görülmektedir. Bununla birlikte, çalışmada mümkün mertebe Tecrîd geleneği dışındaki metinlere başvurulsa da Hikmetü'l-Ayn, Hidayetü'l-Hikme, Işarât, Tevâlî, Mevâkıf gibi şerh geleneklerinin ayrı ayrı çalışma konusu edinilmesi gerektiği anlaşılmaktadır. Böylece umûr-1 âmme sorununa dair müteahhirîn dönemindeki farklı bakış açılarını daha açık bir şekilde tespit etmek mümkün olacaktır. 